\title{
Desconstrução e teologia
}

\section{Déconstruction et théologie}

DOI:10.12957/ek.2015.18282

Dra. Françoise Dastur

fr.dastur@gmail.com

Archives Husserl de Paris tradução Dndo. Victor Dias Maia Soares

victormaiasoares@gmail.com

UERJ

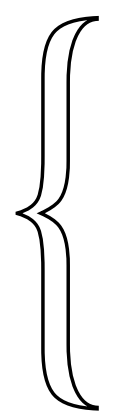

A questão da relação entre desconstrução e teologia, que se tornou mais insistente no "último" Derrida, deu lugar a múltiplos trabalhos. Propõe-se aqui retraçar a gênese desta questão a partir dos primeiros trabalhos de Derrida, nos quais se pode detectar uma tripla influência, aquela da concepção husserliana de Deus, a da desconstrução heideggeriana da história da ontologia e a do pensamento levinasiano do rastro.

PALAVRAS-CHAVE Desconstrução. Teologia. Rastro

The question of the relationship between deconstruction and theology, which has become more insistent in Derrida's last works, has been the object of many commentaries. This paper aims at retracing the genesis of this question in Derrida's first works, in which a triple influence can be found: Husserl's idea of God, Heidegger's deconstruction of the history of ontology, and Levinas' thinking of the trace.

KEY-WORDS Deconstruction. Theology. Trace 
Numerosos textos, particularmente do outro lado do Atlântico ${ }^{1}$, foram já consagrados à questão da relação entre desconstrução e teologia e desconstrução e religião, duas questões que parecem ter se tornado mais insistentes no "último" Derrida. O primeiro texto que aborda de maneira direta estas questões, a saber, "Comment ne pas parler", data de 1986, mas elas serão retomadas e desenvolvidas alguns anos mais tarde, principalmente em Donner la mort (1990), em Saufle nom (1993) e em Foi et savoir (1994). O que se propõe aqui é retraçar sucintamente a gênese dessas questões, das quais se pode dizer que estão já presentes desde o início, e das quais se pode encontrar o rastro em todos os primeiros textos de Derrida.

$*$

Antes mesmo que o termo "desconstrução" se tornasse o eixo temático do pensamento derridiano, a questão da relação entre fenomenologia e teologia já tinha sido abordada na leitura que o jovem Derrida fazia, no decurso dos anos 1950 e 1960, da obra de Edmund Husserl. Ao longo de todo o primeiro texto consagrado a este último, sua dissertação de mestrado, o normalien ${ }^{2}$ Derrida já notava em 1954 que Husserl, embora não tivesse nele "nenhuma intemporalidade" (DERRIDA, 1990, p. 151, nota 57), permanece prisioneiro da tradição clássica, que "compreende a temporalidade sobre o fundo de uma eternidade possível ou atual" (ibid., p. 41). Com efeito, é este pertencimento à tradição clássica que explica "a profundidade estranha de certas semelhanças entre os pensamentos hegeliano e husserliano" (ibid., p. 12), sendo Husserl, tanto quanto Hegel, levado a pensar o "devir do Absoluto" (ibid., p. 209) no quadro de uma "história absoluta e acabada ou de uma teologia constituindo todos os momentos da história" (ibid., p. 185).

É nesta perspectiva que Derrida evoca brevemente, em 1962, na sua longa "Introdução" ao pequeno texto póstumo de Husserl, intitulado L'Origine de la géométrie, os fragmentos, igualmente póstumos, que tratam da questão de Deus (HUSSERL, 1962, p. 161). A consciência transcendental humana é considerada por Husserl, com efeito, como portadora de um "Logos absoluto" e de uma "Razão teleológica" que constituem o polo ideal da sua realização própria. Isto é o que explica que possa aparecer a ideia de uma "divindade

1 Cf., por exemplo, Steven Shakespeare, Derrida and Theology, London, Continuum, 2009; Other Testaments: Derrida and Religion, Yvonne Sherwood e Kevin Hart (Org.), New York, Routledge, 2004; John D. Caputo, The Prayers and Tears of Jacques Derrida: Religion without Religion, Bloomington e Indianapolis, Indiana University Press, 1997.

2 Termo pelo qual são designados os estudantes da École Normale Supérieure, em Paris. (N.T.) 
transcendental" que, ainda que situada para além da história constituída, não é, no entanto, senão "o Polo para si da historicidade e da subjetividade transcendental histórica constituintes" (ibid., p. 164, Derrida sublinha). Acontece que, embora para Husserl a "meta-historicidade do Logos divino", assim como das idealidades que ele caracteriza como "onitemporais"3 em Experiência e julgamento, se confunda com o próprio movimento da história, esta última não pode ser compreendida senão como "a tradição pura de um Logos originário até um Telos polar" (HUSSERL, 1962, p. 165). O que implica uma tal concepção, para a qual "o Absoluto é a Passagem", é que o método que a fenomenologia é enquanto teoria da redução "não é o prefácio neutro ou o exercício preambular de um pensamento, mas o pensamento ele mesmo na consciência da sua historicidade integral" (ibid., p. 166, Derrida sublinha).

É esta mesma questão da relação entre o absoluto e a história que Derrida põe no curso intitulado "Méthode et Métaphysique", que ele deu durante o inverno de 1962-1963 na Sorbonne, onde era assistente, no momento mesmo em que L'Origine de la géométrie 4 era publicada. Ele evocava aí as figuras de Parmênides, pensador do caminho; de Platão, pensador da ideia meta-metodológica do Bem; e, mais longamente, de Descartes, filósofo do método na sua oposição a Espinosa; e, por fim, de Hegel, aquele que renuncia aos infinitismos clássicos, revelando a sua historicidade, e para o qual a própria história se torna método. Eu cito:

"O método se torna com Hegel o próprio logos. O itinerário até a verdade não é nem humano nem extrínseco e estático em Deus. Porque Deus não é passivo, ele está em movimento, ele é a vida. O caminho até a verdade não está nem fora nem na verdade. Ele é a verdade se fazendo. Está aí a evidência fundadora da Fenomenologia do espirito".

Derrida conclui, como na sua dissertação de mestrado, que há uma "cumplicidade profunda entre a filosofia de Hegel e a de Husserl". Com efeito, pode-se

3E. Husserl, Éxperience et jugement, Paris, PUF, 1970 , $\$ 64$ c, p.315-316, onde Husserl afirma que a supra-temporalidade das objetividades do entendimento significa oni-temporalidade, que é um modo da temporalidade.

4Cito os cursos do ano universitário 1962-1963, aos quais assisti enquanto estudante, a partir das notas então tomadas. 
dizer que, no saber absoluto, a intencionalidade se vê absorvida. $\mathrm{O}$ curso termina com estas palavras: "A intencionalidade é ou não um fato irredutível? Tratar-se-ia então de interrogar a filosofia de Husserl no nível da problemática de Deus".

O curso seguinte, da primavera de 1963, intitulava-se precisamente "Fenomenologia, teologia e teologia em Husserl”, e Derrida começava por sublinhar que durante a maior parte do itinerário husserliano Deus não é nomeado senão como index ou como pretexto para confirmar a legitimidade da fenomenologia, de modo que se trata de compreender como e por que o tema de Deus deveria pouco a pouco reaparecer e se impor ao pensamento husserliano, não do exterior, mas, ao contrário, sem ruptura com o projeto inicial da fenomenologia. Após ter analisado longamente o sentido da redução de Deus na primeira fase da fenomenologia, tal como Husserl a apresenta no primeiro volume de Ideias diretrizes - particularmente no famoso §43, que determina como "absurda" a concepção de um Deus que "possuiria naturalmente a percepção da coisa em si que é recusada a nós, seres finitos" (HUSSERL, 1950, p. 138-139) -, Derrida chega ao período dos anos 1920, de uma segunda fase da fenomenologia, na qual o conceito de Deus se vê modificado.

Já parecia claramente, no nível das Ideias diretrizes de 1911, que Deus não pode ser concebido como um ser transcendente, determinando exteriormente a consciência, e que ele também não pode ser considerado como um Deus criador, uma vez que esteja submetido às mesmas leis eidéticas que os seres finitos. Derrida cita então a conferência que Husserl pronunciou em Viena, em maio de 1935, com o título "A crise da humanidade europeia e a filosofia", onde ele afirma que o conceito de Deus implica, do lado do homem, que o seu sentido de ser e de valor seja provado como uma exigência interna absoluta (HUSSERL, 1976, p. 371) $)^{5}$. Derrida concluía que se a consciência descobre assim Deus nele mesmo, e não como o seu fora, esta dimensão ou esta profundidade divina da consciência não é outra senão o próprio transcendental. É preciso falar aqui, portanto, de "deidade" antes que de Deus, porque se trata de reconhecer o seu sentido antes do seu próprio ser. Segundo Derrida, o tema da deidade está ligado ao da objetividade ideal, ao fato de que a consciência que constitui um tal objeto faz aflorar o divino nele mesmo. Ele deve igualmente ser posto em relação com o que Husserl nomeia "ideia no sentido kantiano" (HUSSERL, 1950, §83, p. 281), esta ideia de um infinito não atual, mas de um "ao infinito", quer dizer, da abertura de um horizonte no qual tudo se dá como podendo ser o objeto de uma determinação infinita, Deus aparecendo nesta perspectiva como a abertura

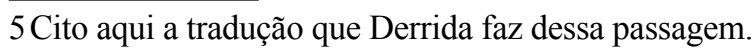


e o fim da história, o seu horizonte. Ele deve, enfim e sobretudo, ser posto em relação com a intersubjetividade, com a comunidade das mônadas - Deus não pode ser uma mônada absoluta, mas o telos que as mônadas representam elas mesmas como fim e valor -, Husserl chegando a afirmar, em um manuscrito que Derrida cita, que "Deus morreria se todos os homens morressem". O curso se concluía com esta fala de Husserl, recordada por Edith Stein: "A vida do homem não é nada mais que um caminho até Deus. Tentei atingir o objetivo sem a teologia, suas provas e seus métodos; em outros termos, quis alcançar Deus sem Deus"6, fala na qual Derrida via o reconhecimento por Husserl de uma inseparabilidade do método e da metafísica, do infinito e da intencionalidade.

Já em 1954, Derrida afirmava que a filosofia de Husserl, que obedece "a um racionalismo e a um idealismo fundamental", apelava a "uma explicação radical que será totalmente uma conversão" (DERRIDA, 1990, p. 41). Esta "conversão" tomará a forma de uma desconstrução, termo que aparece em $A$ voz e o fenômeno (1967), esta Introdução ao problema do signo na fenomenologia de Husserl, como precisa o subtítulo, que Derrida considera então como "o ensaio do qual [ele] mais gosto [a]" e que "viria em primeiro lugar", porque "se coloca aí [...] um ponto [...] decisivo", a saber, a questão do privilégio dado à "presença a si na fala dita viva" (DERRIDA, 1972a, p. 13). O que se trata então de "desconstruir", contra Husserl, é a "transcendência" da voz (DERRIDA, 1967a, p. 58), ao mesmo tempo que a diferença entre significante e significado, presença simples e representação (ibid., p. 57-58) ${ }^{7}$. Mas é na primeira parte da Gramatologia, texto escrito em 1965, que Derrida deixa claro que é preciso compreender "a des-construção" não como "demolição", mas como "des-sedimentação" (DERRIDA, 1967b, p. 21), atestando com isto que ele toma este termo emprestado não somente de Heidegger e do seu projeto de "destruição da história da ontologia" (HEIDEGGER, 1963, §6, p. 19), mas também de Husserl e da empresa que é a sua no último livro, Experiência e julgamento, a saber, a de uma genealogia da lógica que tem por objetivo exumar, sob "os depósitos de operações subjetivas” (HUSSERL, 1970, p. §11, p. 56) que dão ao mundo o

6Cf. Édith Stein, Par une moniale française, Paris, Seuil, 1954, p. 113, citado por René Toulemont, L'Essence de la société chez Husserl, Paris, PUF, 1962, p. 303.

7 Françoise Dastur diz "representação" (représentation) onde se lê em Derrida "reprodução" (reproduction) (N.T.). 
seu sentido atual, a fonte originária sobre a qual está fundado e que não é outra senão o que ele nomeia "experiência antepredicativa" (ibid., §6, p. 30). É acerca disto que Husserl utiliza o termo "Abbau", traduzido aqui por "desmantelamento", das idealizações científicas, em vista de fazer retornar à sua fonte originária - que não é outra senão a doxa - que se vê aí legitimada, ao encontro de toda a tradição filosófica, como o domínio último e original onde o conhecimento científico extrai o seu sentido (ibid., §10, p. 53-55).

É em um sentido análogo que Heidegger compreende o que nomeia em Ser e tempo "destruição", que ele esclarece não ter o sentido negativo de uma rejeição ou de uma liquidação (Abschüttelung) da tradição ontológica, mas o de uma eliminação (Ablösung) dos revestimentos (Verdeckungen) que ela acumulou com o tempo (HEIDEGGER, 1963, p. §6, p. 22). Heidegger não utiliza aqui o termo "Abbau", desconstrução, mas este aparece no curso que ele fará no mesmo ano sobre Os problemas fundamentais da fenomenologia (1927), que não será publicado senão em 1975 (HEIDEGGER, 1985, §5, p. 41), do mesmo modo que nos cursos seguintes, os dos anos 1928 e 1929-1930 ${ }^{\circ}$. Encontra-se este termo, contudo, nos textos dos quais Derrida pôde tomar conhecimento no decurso dos anos de 1960. É o caso da conferência pronunciada por Heidegger em Cerisy (1955), sob o título O que é isto, a filosofia?, cujo texto foi publicado em 1956 e traduzido para o francês em 1957, e onde Heidegger recorda que em Ser e tempo "Destruição não significa aniquilação (Zerstören), mas desmontar (Abbauen), demolir (Abtragen) e pôr de lado (Auf-die-Seite-stellen)" (HEIDEGGER, 1957, p. 38) $)^{9}$. Mas é, sem dúvida, o texto publicado em 1956 e intitulado "Contribuição à questão do ser" - texto capital para Derrida, pois nele Heidegger "não deixa ler a palavra 'ser' senão sob uma cruz", "rasura" na qual ele vê a "última escrita de uma época", que "de-limita a onto-teologia, a metafísica da presença e o logocentrismo" (DERRIDA, 1967b, p. 38) - que ele sem dúvida encontrou, numa passagem onde Heidegger lamenta a "compreensão superficial da Destruktion exposta em Ser e tempo", que se tratava de compreender como a "Des-construção de representações banais e vazias", a fim de "recuperar as provas do ser que estão na origem daquelas da metafísica" (HEIDEGGER, 1968, p. 240).

Certamente, a desconstrução derridiana não corresponde de modo algum à definição que Heidegger dá da desconstrução, enquanto esta tem por objetivo

8M. Heidegger, Metaphysische Anfangsgründe der Logik, GA 26, Frankfurt, Klostermann, 1978, p. 27 (curso do semestre no verão de 1928) e Die Grundbegriffe der Metaphysik, GA 29/30, Frankfurt, Klostermann, 1978, p. 27; curso do semestre no inverno de 1929-1930, §60, p. 371.

9Lembramos que Derrida não estava presente no Colóquio de Cerisy consagrado a Martin Heidegger, em agosto de 1955. 
reconduzir, como já o dizia o $\S 6$ de Ser e tempo, "às experiências originais nas quais foram alcançadas as primeiras determinações do ser, que permaneceram consequentemente diretivas" (HEIDEGGER, 1963, p. 22, eu sublinho), isto não seria assim senão porque o conceito de experiência, que, como Derrida o sublinha na Gramatologia, "sempre designou a relação a uma presença" (DERRIDA, 1967b, p. 89), deve ser ele mesmo submetido à desconstrução. Mas também porque, desde esta época, e ainda que Levinas não seja citado senão uma única vez no ensaio de 1967 (ibid., p. 103), são a "crítica da ontologia" e o conceito de "rastro" deste último que vão se tornar o horizonte determinante do pensamento derridiano. No longo ensaio que lhe consagrou em 1964, sob o título "Violência e metafísica", Derrida já sublinhava, com efeito, que se encontra em Levinas uma maneira de compreender a experiência que se poderia dizer "meta-teológica, meta-ontológica, meta-fenomenológica" (DERRIDA, 1967c, p. 127), como "passagem e saída para o outro" no "que há de mais irredutivelmente outro: outrem" (ibid., p. 123), como "encontro do absolutamente outro" (ibid., p. 140). Este encontro que não tem "a forma do contato intuitivo", mas "aquela da separação", aquela de um "para além" que está, no entanto, "presente", mas como "rastro", define o caráter "escatológico" da experiência "pela origem e, de parte a parte, antes de todo dogma, toda conversão, todo artigo de fé ou de filosofia" (ibid., p. 141-142, Derrida sublinha). Que ninguém se engane, "A escatologia messiânica na qual Levinas se inspira", afirma Derrida, não se desenvolve nem como uma teologia, nem como uma mística, nem como uma religião, mas "quer se fazer entender em um recurso à própria experiência" (ibid., p. 123, Derrida sublinha). Derrida mostra ainda aqui, porém, que a metafísica de Levinas pressupõe a fenomenologia transcendental que ela quer pôr em questão, pelo fato de que, a forma irredutível de toda experiência sendo a egoidade, este $a$ priori subjetivo precede o ser de tudo o que é para mim, compreendido aí Deus. O texto ao qual ele faz referência aqui é uma passagem de Lógica formal e lógica transcendental, onde Husserl afirma que "Deus, ele também, é para mim o que é para minha própria efetuação de consciência”, o que não quer dizer, no entanto, que "eu invento e que faço essa transcendência suprema" (HUSSERL, 1957, p. 336). Encontra-se aqui a ideia de que, antes de todo discurso sobre Deus, a divindade de Deus, tal como a alteridade infinita do outro, deve ter um sentido para um ego em geral. Trata-se então, portanto, de ter em conta o "poder de resistência às críticas de Levinas" do discurso husserliano, mas a legitimidade do seu questionamento da fenomenologia transcendental não se mostra, contudo, menos radical a Derrida (ibid., p. 194, nota 1), que parece aqui prestes a seguir a questão assim posta por Levinas, "na inversão da dissimetria transcendental" 
pela qual o outro se torna anterior ao mesmo, à própria filosofia (DERRIDA, 1967c, p. 194 e p. 196). Encontra-se já aqui, portanto, em 1964, a matriz deste pensamento do "messiânico sem messianismo", compreendido como "pensamento do outro e do acontecimento por vir", e como "estrutura universal" da experiência que ele começará a desenvolver, quase trinta anos mais tarde, em Espectros de Marx (DERRIDA, 1993a, p. 102, p. 112, p. 266).

Não obstante, Derrida não pode desenvolver a sua própria concepção da desconstrução senão sobre a base da de Heidegger, na peugada da qual ele se situa quando declara, por exemplo, que desconstruir a filosofia seria fazer a genealogia dos seus conceitos da maneira mais interior, mas, ao mesmo tempo, a partir de um certo fora (DERRIDA, 1972a, p. 15); e, igualmente, quando ele recorda que Heidegger teve que se servir da linguagem metafísica no momento mesmo em que ele a desconstruía (ibid., p. 19). Ele sublinha com pertinência que, desde 1935, na Introdução à metafísica, Heidegger "renuncia ao projeto e à palavra ontologia" (DERRIDA, 1967b, p. 36), uma vez que se trate então para ele de pensar o retraimento do ser, a sua ocultação na própria aparição do ente, única base sobre a qual ele pode ser questão de "uma história do ser", a determinação do ser como transcendente e a abertura da ontologia fundamental em Ser e tempo não tendo sido senão momentos certamente "necessários, mas provisórios" (idem). É, portanto, necessário “passar pela questão do ser, tal como ela é posta por Heidegger, e unicamente por ele, para e além da onto-teologia" (ibid., p. 37, Derrida sublinha) para aceder ao pensamento do rastro, quer dizer, aquele de um para além do ser.

O conceito de rastro que, na Gramatologia, serve de base ao seu próprio conceito de escrita, Derrida o toma emprestado de Levinas, que em "O rastro do outro" já esboça todo um pensamento da escrita ${ }^{10}$. Derrida indica então que a escolha deste termo lhe foi imposta pelos discursos contemporâneos, mas o primeiro nome que ele menciona, antes dos Nietzsche e Freud, é o de Levinas, do qual recorda a definição: "relação à eleidade como à alteridade de um passado que não foi nunca e não pode jamais ser vivido na forma originária ou modificada da presença" (DERRIDA, 1967b, p. 103). Com efeito, em "O rastro

10Lembremos que Derrida esclarece em uma nota de "Violência e metafísica" que só pôde fazer breves alusões ao texto de Levinas intitulado "La trace de l'autre" [O rastro do outro], publicado em setembro de 1963, no momento em que Derrida acabava de escrever o seu ensaio. 
do outro", Levinas insiste sobre o fato de que o emprego do pronome "Ele", que designa "o absolutamente Ausente" no seu passado irreversivelmente passado, reenvia a "toda enormidade, toda desmesura, todo o Infinito do absolutamente outro, escapando à ontologia" (LEVINAS, 1967, p. 199). E conclui, evocando Plotino e a sua concepção da procissão a partir do Uno, que "só um ser transcendendo o mundo pode deixar um rastro" (ibid., p. 201). Porque, se o rastro pode certamente se tornar um signo, tomando lugar no mundo e reenviando com isso a uma significação, ele não é propriamente senão "a passagem daquele que emitiu o signo", e, enquanto tal, não revela nem dissimula nada, porque "ser enquanto deixar um rastro é passar, partir, se absolver" (ibid., p. 200, Levinas sublinha). Levinas, com efeito, não recua diante do emprego da palavra "ser" para falar da eleidade. De fato, ele não define o rastro como "a própria indelebilidade do ser [...] sua imensidade incapaz de se fechar em si e, de alguma maneira, demasiado grande para a discrição, para a interioridade, para um Si" (idem)? É em consonância com esta concepção do rastro que Derrida poderá definir o que ele próprio nomeará, para arrancá-lo da ordem da presença e da entância, "arqui-rastro" (DERRIDA, 1967b, p. 90), "a abertura da primeira exterioridade em geral, a enigmática relação do vivente com o seu outro e de um dentro com um fora" (ibid., p. 103). Mas este fora, esta exterioridade, é a do outro, daquele que é radicalmente transcendente ao mundo e que não se mostra senão pelo seu rastro e que Levinas nomeia, no fim de "O rastro do outro", "o Deus revelado da nossa tradição judaico-cristã" (LEVINAS, 1967, p. 103).

É evidente que a empresa que é a de Derrida em 1967, a saber, a constituição, sob o nome de "gramatologia", de uma ciência ou de uma filosofia da escrita, não dá por pressuposta a tradição judaico-cristã. Com efeito, Derrida toma o cuidado de precisar que se trata para ele de dar à noção de rastro, concedendo-a uma "intenção heideggeriana" e desvinculando-a, portanto, "do pensamento de Levinas" a significação do "abalamento de uma ontologia que [...] determinou o sentido do ser como presença e o sentido da linguagem como continuidade plena da fala" (DERRIDA, 1967b, p. 103). A desconstrução, tal como ele a compreende, visa ao abalamento da ontologia e da metafísica da presença (ibid., p. 73), e é porque ela abala "as seguranças da onto-teologia", quer dizer, da determinação de Deus como ente supremo e logos absoluto, e porque ela contribui para "deslocar a unidade de sentido do ser" (ibid., p. 3536), que é necessário passar pelo pensamento heideggeriano do ser, para vir a reconhecer que o ser não é um significado transcendental, como o implica a 
noção de diferença ôntico-ontológica, mas um rastro significante (ibid., p. 38) ${ }^{11}$. Para o pensamento da não-diferença entre significado e significante, o que ele nomeará em seguida "différance", trata-se, portanto, para Derrida, de ir ainda mais longe do que Heidegger em sua crítica da onto-teologia, na época em que este último está ainda preso, na medida em que o logocentrismo, quer dizer, a subordinação do significante ao significado, da escrita à linguagem falada, não está completamente ausente do pensamento (ibid., p. 23). O que se trata, então, de desconstruir é o teologismo da tradição metafísica, que "constituiu o obstáculo maior a toda gramatologia" (ibid., p. 112). Todas as teologias infinitistas são, com efeito, logocentrismos, afirma aqui Derrida, porque "Só o ser infinito pode reduzir a diferença na presença" e "Só o infinito positivo pode suspender o rastro, "sublimá-lo", e é na filosofia de Hegel, esta "teologia do conceito absoluto como logos" (ibid., p. 104), que ocorre a sublimação ou Aufhebung do rastro, que essa essência basicamente teológica do logocentrismo aparece em plena luz.

Compreende-se a partir disso que, para Derrida, se trata de fazer portar a des-construção sobre a metafísica logocêntrica e o seu conceito de episteme, quer dizer, sobre a totalidade da tradição filosófica (ibid., p. 68), num gesto análogo ao de Levinas, mas também ao de Heidegger, que pronunciou em 1964 uma conferência precisamente intitulada "O fim da filosofia e a tarefa do pensamento" (HEIDEGGER, 1968, p.112 seq.). Derrida, com efeito, conclui a primeira parte do seu ensaio, de 1967, afirmando que um pensamento do rastro "deve também apontar para além do campo da episteme", de modo que apareçam os limites do projeto perseguido aqui, o de uma ciência da escrita, de uma gramato-logia, quer dizer, de um pensamento ainda "encerrado na presença" (ibid., p. 142). Como ele o precisa em Posições, "jamais foi questão de opor um grafocentrismo a um logocentrismo", porque "Não se instala nunca numa transgressão, não se habita nunca algures", de modo que "Gramatologia não é uma defesa e ilustração da gramatologia", mas "o título de uma questão" (DERRIDA, 1972a, p. 21-22). Não obstante, mesmo tomado na clausura da metafísica, uma clausura que "não terminará talvez nunca", a desconstrução produz nela "a brecha pela qual se deixa entrever, ainda inominável, a luz da além-clausura" (DERRIDA, 1967b, p. 25, Derrida sublinha). Esta luz, seguramente, não é para Derrida a do pensamento heideggeriano da "clareira" do ser, que, sob o nome Ereignis, rompe decisivamente com a ideia que comandou toda a história ocidental, a do ser pensado como absoluto - do que mantém ligação com alguma outra coisa -, em proveito

110 "segundo" Heidegger não deixará, aliás, de considerar a diferença ontológica, porque ela pode conduzir à representação do ser como um ente, como um "impasse necessário". Cf. a este respeito M. Heidegger, "Les séminaires du Thor" (1969), in Questions IV, Paris, Gallimard, 1976, p. 63-64. 
de um co-pertencimento do ser e do homem (HEIDEGGER, 1968, p. 264), e, portanto, de uma finitude própria ao ser ele mesmo. É, em vez disso, aquela obscura, e mesmo tenebrosa, de "Autrement qu'être" que unicamente torna possível o pensamento do rastro "onde se marca a relação ao outro", o qual "se apresenta na dissimulação de si", e de que é preciso então reconhecer que "o teológico" constitui "um momento determinado" (DERRIDA, 1967b, p. 69).

Não é preciso, portanto, se espantar de ver reaparecer em seguida, na obra de Derrida, a questão da relação entre o pensamento do rastro e da différance e da teologia. Certamente, não a teologia tradicional, para a qual Deus é o ente supremo, mas a teologia dita "negativa", que constitui por assim dizer o inverso, e que consiste em insistir mais sobre o que Deus não é do que sobre o que Deus é. Derrida teve que precisar, já na sua conferência de 1968 sobre "A différance", que, quando diz que a différance não é, o seu discurso não releva da teologia, e "nem mesmo a ordem mais negativa da teologia negativa, estando ela sempre ocupada, como se sabe, com a evidenciação de uma supra-essencialidade para além das categorias finitas da essência e da existência, quer dizer, da presença" (DERRIDA, 1972b, p. 6). É este risco implicado por um pensamento do rastro e da différance, o de uma "interminável "teologia negativa"” (DERRIDA, 1972c, p. 11), que Derrida escolhe enfrentar diretamente em 1986, na sua conferência de Jerusalém "Comment ne pas parler", cujo subtítulo "Dénegations" aponta para o seu título em inglês "How to Avoid Speaking", como evitar falar, quer dizer, "retardar o momento em que se deverá então dizer alguma coisa e talvez confessar, contar, confiar um segredo" (DERRIDA, 1987, p. 549). Este segredo é aquilo pelo que ele, embora afirme categoricamente que o que escreve não se insere no âmbito da "teologia negativa", confessa ter sido sempre "fascinado" pelo que recobre esta denominação (ibid., p. 545).

Porque, após ter recusado se inscrever na peugada da teologia negativa em razão do "sobrelanço ontológico da hiper-essencialidade" (ibid., p. 541), tanto na obra de Dionísio, o Areopagita, quanto na de Eckhart, e ter afirmado que o pensamento da différance tem pouca afinidade com uma abordagem apofática que tende à "união silenciosa com o inefável" (ibid., p. 544), não deixa de ser verdade que a via negativa no seu momento cristão tem "o interesse de definir um para além que excede a oposição entre a afirmação e a negação" (ibid., p. 
552), de modo que é preciso reconhecer à hiper-essencialidade de Deus o valor ambíguo de um "além do ser" e de um "mais que ser". Isso é o que constitui a atopia de Deus, "que não é nada porque tem lugar, sem lugar, para além do ser" (ibid., p. 559, Derrida sublinha). Quanto ao próprio discurso apofático, ainda que não diga nada, ele tem lugar, e não pode nomear Deus senão porque este último é, como sublinha Dionísio, o Areopagita, aquele "que concede em primeiro lugar o poder de falar e de bem falar", de modo que é preciso reconhecer que o que diz o nome de Deus é "o rastro deste singular acontecimento que terá tornado a palavra possível antes mesmo que esta retorne, para aí responder, para esta primeira ou última referência" (ibid., p. 560, Derrida sublinha). Derrida encontra aqui o pensamento levinasiano do rastro, aquele de uma injunção vinda do outro e de um "passado que jamais foi presente e permanece, portanto, imemorável" (ibid., p. 561), deixando claro, no entanto, que a distinção entre uma causa finita e uma causa infinita do rastro é aqui secundária. Porque o pensamento do rastro é aqui posto em relação com um motivo de pensamento que se encontra no último Heidegger, o da "linguagem que começou sem nós, em nós antes de nós" e que, segundo Derrida, "a teologia apela a Deus"12. É, com efeito, ao pensamento de Heidegger que Derrida consagra o fim da sua conferência, após ter analisado os paradigmas grego e cristão da teologia negativa - a saber, a khôra platônica, na qual ele vê a referência a um "absolutamente outro" [tout autre], "estrangeiro à ordem da presença e da ausência" (ibid., 570) e o pensamento, em Mestre Eckhart, de um "Deus [...] sem nome", e mesmo de um "Não-Deus" (ibid., 583) - e ter decidido, denegação final, não falar "dos movimentos apofáticos nas tradições judia e árabe" (ibid., 584), ainda que a via da teologia negativa se encontre aí, para assim dizer, pré-traçada, particularmente no judaísmo, que não nomeia Deus senão por um nome impronunciável, de maneira a preservar a sua fundamental inefabilidade. Para Derrida, com efeito, não há diferença entre "escrever ser, este ser que não é; e escrever Deus, este Deus do qual Heidegger diz também que não é”, de modo que não haveria aí "diferença entre escrever uma teologia e escrever sobre o ser, do ser, como Heidegger não cessou de fazê-lo" (ibid., 592, Derrida sublinha). Afirmação que Heidegger contestaria sem nenhuma dúvida, ele que diz na Carta sobre o humanismo, o próprio Derrida o lembra, que o ser não é nem Deus nem um fundamento do mundo (HEIDEGGER, 1964, p. 77), e que não é senão a partir da verdade do ser que pode ser pensado e dito o que deve nomear a palavra "Deus"

12 Cf. M. Heidegger, Acheminement vers la parole, trad. fr. François Fédier, Paris, Gallimard, 1976, p. 254: "O ser humano só é capaz de falar na medida em que, pertencendo ao Dito (Sage), ele se dispõe a ouvir a fim de poder, em seguida, dizer uma palavra". 
(ibid., p. 135). A nominação de Deus pressupõe para Heidegger, portanto, a clareira do mundo, que forma o centro do Geviert, da Quaternidade, que remete à cruz pela qual Heidegger borra a palavra ser, o divino não formando senão uma das regiões do mundo e não sendo de forma alguma o centro ${ }^{13}$.

Porque, para Derrida, trata-se de entender o epekeina tes ousias de Platão não como o faz Heidegger, a saber, como o para além da totalidade do ente, quer dizer, como o ser ou o mundo, tais como são definidos em Ser e tempo, mas como o para além do próprio ser, como o faz a teologia negativa, que encontra nesta afirmação a sua própria origem. O que, explicava Derrida em Sauf le nom (1993), significa a abertura não somente de um para além do ser e de Deus, compreendido como ente supremo, mas também do nome mesmo de Deus, este próprio nome parecendo aí, por vezes, "não estar mais a salvo..." (DERRIDA, 1993b, p. 74). Porém, para o próprio Derrida, este para além do ser não reenvia à exterioridade de um Absolutamente-Outro infinito, mas, como ele sugeria em "Donner la mort" (1990), seria preciso, ao contrário, dizer que "Deus é o nome da possibilidade para mim de guardar um segredo que é visível ao interior, mas não ao exterior", porque, "desde que tenho em mim, graças à palavra invisível como tal, um testemunho que os outros não veem, e que é, portanto, ao mesmo tempo diferente de mim e mais íntimo a mim do que eu mesmo, [...] há o que chamo Deus" (DERRIDA, 1992, p. 101-102, Derrida sublinha). Ele se manifestaria, então, na sua própria não-manifestação, quando nasceria no ser vivente "o desejo e o poder de tornar absolutamente invisível e de constituir em si um testemunho dessa invisibilidade” (ibid., p. 102).

Compreende-se, então, que Derrida possa dizer da teologia negativa - é a última frase de Saufle nom, texto consagrado ao Pèlerin chérubinique d'Angelus Silesius, que Heidegger cita várias vezes em Le Principe de raison"14: "Ela mantém o desejo na expectativa e, dizendo sempre demasiado ou demasiado pouco, vos deixa a cada vez sem deixar-vos jamais" (DERRIDA, 1993b, p. 114).

13 M. Heidegger. "La chose" [1950], em Essais et conférences, trad. fr. André Préau, Paris, Gallimard, 1958, p. 212: "Se nomeamos os divinos, pensamos os três outros com eles"; e p. 214: "o jogo de espelho da simplicidade da terra e do céu, dos divinos e dos mortais, nós o nomeamos "o mundo"”.

14M. Heidegger, Le Principe de raison, Paris, Gallimard, 1962, p. 103-109, p. 112, p. 115, p. 141, p. 159 
DERRIDA, J. La Voix et le phénomène. Introduction au problème du signe dans la phénoménologie de Husserl. Col. "Quadrige Grands Textes". Paris: PUF, 1967a.

. De la grammatologie. Col. "Critique". Paris: Minuit, $1967 \mathrm{~b}$.

. L'Écriture e la différence. Col. "Tel Quel".

Paris: Seuil, 1967c.

.Positions. Col. “Critique”. Paris: Minuit, 1972a.

. Marges. De la philosophie. Col. "Critique".

Paris: Minuit, 1972b.

La Dissémination. Col. "Tel Quel”. Paris:

Seuil, 1972c.

. Psyché. Inventions de l'autre. Col. "La philosophie en effet". Paris: Galilée, 1987.

Le Problème de la genèse dans la philosophie de Husserl. Col. "Épiméthée". Paris: PUF, 1990.

.'Donner la mort", in L'Étique du don. Jacques

Derrida et la pensée du don. Colloque de Royaumont 1990, Jean-Michel Rabaté e Michel Wetzel (org.). Paris: Métailié-Transition, 1992.

. Spectres de Marx. L'État de la dette, le travail du deuil e la nouvelle Internationale. Col. "La philosophie en effet". Paris: Galilée, 1993a.

. Sauf le nom. Col. "Incises". Paris: Galilée, 1993b.

HEIDEGGER, M. Qu'est-ce que la philosophie? Trad. fr. Kostas Axelos e Jean Beaufret. Paris: Gallimard, 1957. . Sein und Zeit. Tübingen: Niemeyer, 1963.
. Lettre sur l'humanisme. Trad. fr Roger Munier. Paris: Aubier, 1964.

. "Contribution à la question de l'être". Trad. fr. Gérard Granel, in Questions, Paris: Gallimard, 1968. Les Problèmes fondamentaux de la phénoménologie. Trad. fr. Jean-François Courtine. Paris: Gallimard, 1985.

HUSSERL, E. Idées directrices pour une phénoménologie. Trad. fr. Paul Ricœur. Paris: Gallimard, 1950.

. Logique formelle et logique transcendantale. Paris: PUF, 1957.

. L'Origine de la géométrie. Tradução e introdução por J. Derrida. Col. “Épiméthée”. Paris: PUF, 1962. . La Crise des sciences européennes et la phénoménologie transcendentale. Trad. fr. Gérard Granel, Paris: Gallimard, 1976.

LEVINAS, E. En découvrant l'existence avec Husserl et Heidegger. Paris: Vrin, 1967.

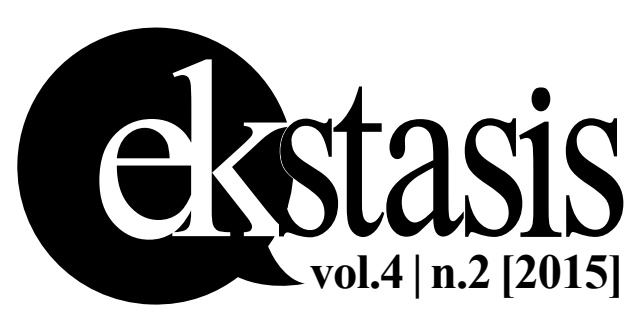

